\title{
Research and practice of green highway construction technology system
}

\author{
Xiaohua Xiong ${ }^{1}$, Longsheng Zhang ${ }^{2}$, Jianping $\mathrm{Gao}^{3}$, Dan Wang ${ }^{4}$, Shegang Shao ${ }^{4}$ and Tianwen Liang ${ }^{4}$ \\ ${ }^{1}$ Jiangxi communications consulting company \\ ${ }^{2}$ Guangchang Ji'an Expressway Construction Project Office of Jiangxi Expressway Investment Group Co., Ltd \\ ${ }^{3}$ Hukou branch of Jiujiang Highway Bureau \\ ${ }^{4}$ Research Institute of Highway Ministry of Transport, Beijing, 100086, China
}

\begin{abstract}
Taking Guangji expressway as an example, this paper focuses on the goal of building "demonstration road of highway construction, demonstration road of green highway and demonstration road of quality engineering" in Jiangxi Province. It mainly describes the construction idea, realization way, characteristics, highlights and practical experience of demonstration project of Guangji green highway construction.
\end{abstract}

\section{Introduction}

In 2016, the Ministry of transport deployed to carry out the construction of typical demonstration projects of green highway construction, and issued the guiding opinions on the implementation of green highway construction, clarified the development ideas and construction objectives of green highway, and promoted the transformation and upgrading of highway construction. Jiangxi Guangchang Ji'an Expressway Project (hereinafter referred to as "Guangji project") is listed as the first batch of green highway typical demonstration projects. The author personally participates in the construction management and green highway practice of the project, and has a lot of experience. His understanding of the concept of green highway is more clear and in-depth. Now it is sorted out and written to share with you.

\section{Construction of typical demonstration projects of Guangji Expressway Green Highway}

Guangji expressway is a section of the seventh connecting line between Putian of Fujian Province and Yanling of Hunan Province (G1517) of Shenhai expressway of national expressway network, and also the third horizontal section of the main framework of "four vertical, six horizontal, and eight shooting" of Jiangxi expressway network. The total length of the route is $189.276 \mathrm{~km}$, and the project budget is 12.624 billion yuan. The natural environment of the area where the project passes is beautiful and the ecological environment is good, "green, red and ancient" tourism resources are rich. The construction of the project was officially started in early 2016, and it is planned to be completed and opened to traffic in January 2019. The green road construction has achieved initial results, and the typical demonstration effect has initially appeared. In October 2018, relying on the typical demonstration project of Guangji high speed green highway, China highway society held the fourth green highway technology forum in Jiangxi Province. Representatives attended the forum and paid a visit to the site. They highly appraised the construction concept, demonstration features, highlights and implementation effect of the typical demonstration project of Guangji high speed green highway.

\section{Construction ideas of demonstration project}

Since the commencement of the project, focusing on the goal of building Jiangxi "highway construction demonstration Road, green highway demonstration road and quality engineering demonstration road", all participants of Guangji expressway construction project take green as the soul and quality as the core, through high starting point planning layout, high realm concept design, high-quality construction implementation, highlevel environmental protection and all-round innovation driven We will fully implement the concept of "green highway", vigorously advocate the spirit of craftsman, actively encourage public innovation, strictly supervise quality and safety, seek breakthroughs and innovation, draw high-speed pictures, and strive to build Guangji Expressway into a "Jiangxi model" of green highway and quality engineering. 


\section{The way to realize the demonstration project}

Based on the features of project function, project and environment, the typical demonstration project of Guangji high-speed green highway has made a breakthrough in three aspects: green highway demonstration, quality project building and construction project management improvement, which has achieved the goal of collaborative building of green highway and quality project. It has set up a model for exploring the road of green development, high-quality development and efficient development of highway construction.

\section{Features and highlights of demonstration project}

The typical demonstration project of Guangji high-speed green highway focuses on five aspects of resource conservation, ecological environment protection, quality construction, service improvement and innovation drive, focuses on 14 key demonstration contents such as land resource protection, implements four special actions such as green construction, and forms or applies 33 "four new" technology and management innovation.

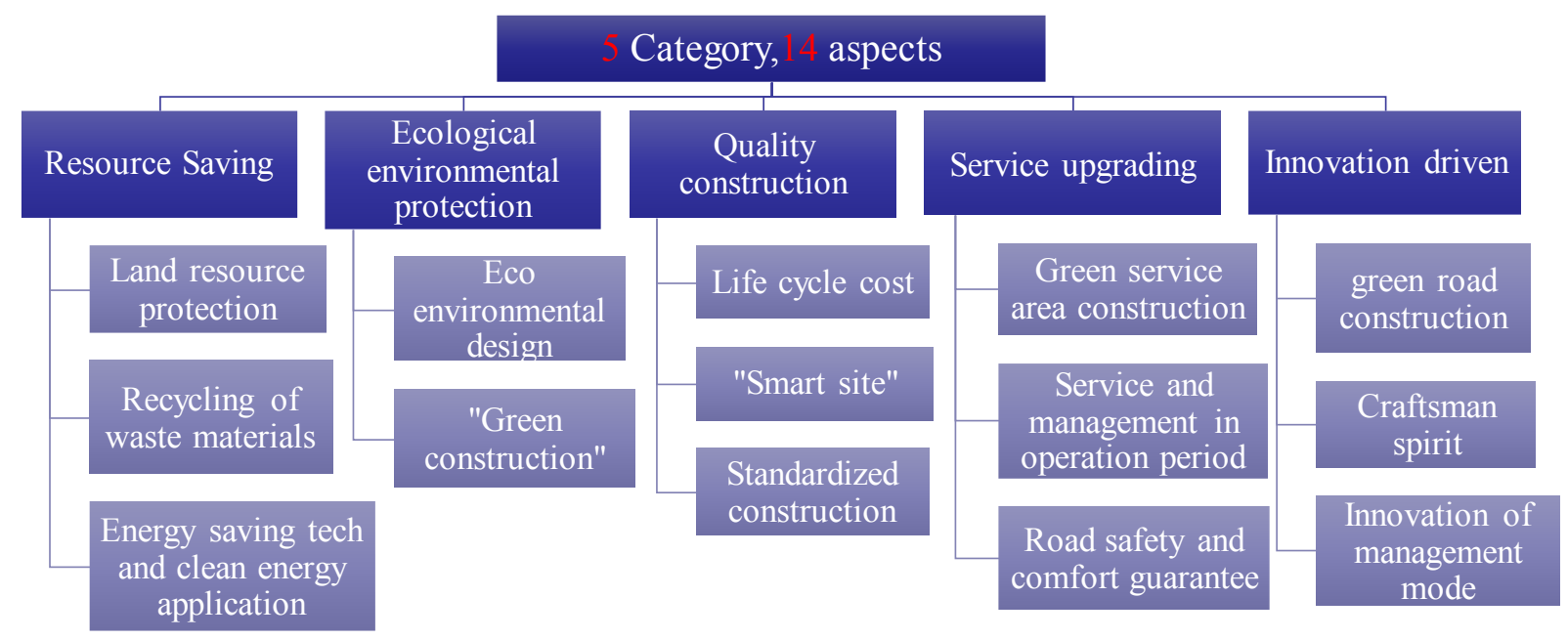

Figure 1. Project demonstration content

The characteristics and highlights of the typical demonstration project of Guangji high speed green highway are as follows:

First, fully implement the concept of "green construction" and management and control technology. In the construction stage, the concept of green road shall be implemented to form a reproducible and popularized standardized construction guide for Green Road, including: combining all-round permanent and temporary land conservation, innovatively proposing the special design and construction management mode of borrow (spoil) ground, popularizing and applying the concept and technology of near natural ecological restoration of Engineering wounds, and carrying out the monitoring, monitoring and management of dust pollution in construction Control technology, innovative application of environmental (water) conservation target management during construction, research on green highway construction standardization, implementation of green production technology of asphalt, etc.

Second, strive to build the first rubber asphalt pavement entity project in Jiangxi and the second longest in China. Integrated use of rubber powder modified asphalt pavement construction and green production technology, to achieve the industrialization and green production of rubber asphalt pavement. In the $70 \mathrm{~km}$ section of $\mathrm{K} 1+567-\mathrm{k} 70+993$, the double-layer rubber powder composite modified asphalt pavement is adopted. On the one hand, the recycling of 120000 waste tires is realized, on the other hand, the high and low temperature performance of the asphalt pavement is improved, and the road noise is reduced.

Third, actively explore the construction technology of green sponge service area to build the fifth generation high-speed service area in Jiangxi. Relying on the construction of Taihe North service area, we carried out a special research on the construction technology of green sponge service area, introduced the "green building" standard, and built it according to the green building standard for the first time in the construction history of Jiangxi service area, reaching the "one star" level green building standard; using the construction concept of "sponge city" for reference, through the application of infiltration, stagnation, storage, purification, use, drainage and other technologies It has built the first sponge service area in China.

Fourth, we should fully promote the spirit of craftsmanship and organize "micro innovation" activities. With reference to the introduction of new equipment, improvement or improvement of construction methods and processes, encourage front-line workers to participate in the construction of green roads and quality projects. Guangji high speed project office has demonstrated and evaluated nearly 50 "micro innovation" achievements, 14 of which have won first, second and third prizes and excellent prizes respectively, greatly encouraging the enthusiasm of front-line workers. 


\section{Practical experience of demonstration project}

"Green road construction" is essentially an important measure of supply side reform in road construction. China's highway construction, especially the highway construction, has made brilliant achievements, providing the basic conditions and strong power for the national economic and social development, and will still strongly promote China's economic and social development for a long time in the future. However, the previous rough construction mode has been unsustainable. The current conditions of resources, energy and environment require that the road construction must change its mode, make full use of resources, intensively save land, protect ecological environment, and improve the life cycle cost. Through innovation driven and demonstration leading, the road can be better constructed and improved under the external constraints of resources, energy and environment Highway construction level.

The construction of "green road" is not only the goal of the road construction industry or the transportation industry, but also the common demand of the development of the whole society. It needs not only our efforts, but also the common support of the whole society.

\subsection{Further mobilize the enthusiasm of highway construction enterprises}

In terms of the industry, since the Ministry of transport put forward "six persistence and six establishment" in the design, the design enterprises have made great progress in the design; however, the construction enterprises still have deficiencies in the understanding of "green road". There are both subjective and objective reasons for this. At present, there are many construction enterprises in China with high competitive pressure and low profit margin, and there is no basic condition and power to implement "green road".

\subsection{Further play the role of cost, bidding and credit evaluation}

In order to realize "green road", all parties of project construction have more social responsibilities to some extent, but the existing project quota has not been fully considered, and the project budget, bidding price limit and bidding price of construction enterprises based on the quota can't be more considered. "Green road" and "intelligent transportation" put forward higher standards and requirements for environmental protection, greening, mechanical and electrical, housing construction projects, etc., but the existing project quota is insufficient. Similarly, the bidding system and credit evaluation system of highway engineering can take targeted measures to encourage highway construction enterprises to participate in the construction of "green highway" more actively, and encourage all parties involved in the construction of the project to take more active social responsibility.

\subsection{Need further support from other industries}

First, the road project "going out" learning from the successful experience of other industries helps to enrich the connotation of "green road" and improve the quality of road construction. The "green building" in the construction industry has a great inspiration and help for us to build "green road". The standardization construction of high-speed railway project also greatly promotes the standardization construction of expressway.

Second, there are many industries involved in highway project construction, such as environmental protection, water and soil conservation, project audit, etc., which have an important impact on project construction and completion acceptance. These industries have their own industry standards. How to coordinate and win support is crucial for green highway construction.

\section{Conclusion}

After more than three years of construction, the demonstration tasks of typical demonstration projects of green highway are progressing smoothly and the construction objectives are preliminarily realized under the full cooperation and efforts of the construction management, design, construction and supervision units. In general, the construction of green roads is based on local conditions, the implementation of the whole process is the key, scientific and technological innovation is the support, and full participation is the guarantee. Only in this way, the construction of typical demonstration projects of green highway can be carried out smoothly, and the construction objectives can be achieved as scheduled.

\section{Reference}

1. Tx Chen. (2018) Construction key technology and application based on green highway concept. Highway transportation technology (application technology version), 14: 9-10.

2. Lx Wang. (2017) Key technology and application of green highway construction under low carbon concept. Private technology, 4: 140-141.

3. N Li. (2017) Analysis of key technical points of green highway construction under the concept of low carbon. Transportation world, 8: 136-137.

4. Zn Ma. (2006) Discussion on the research system of green highway. Highway transportation technology, 9: 146-149.

5. Xd Xing. (2019) Discussion on green highway construction under the low carbon concept. Science and technology innovation, 11: 127-128.

6. Jt Qian. (2017) Discussion on green highway construction under low carbon concept. Engineering technology research, 6: 187-188

7. Xc Qin. (2010) Discussion on key technology and application of green highway construction under the low carbon concept. Highway transportation 
technology (Application Technology Edition),6: 308-310.

8. T Liu. (2019) Practice of green highway in expressway design. China Hi tech,15: 49-51

9. Jq Yuan. (2019) Application of green highway construction concept in highway design. Tianjin construction technology, 29: 103-104

10. Yw Wang. (2019) Practice and experience of typical demonstration project construction of Huiqing Expressway Green Highway. China highway society. Paper collection of the second National Quality Engineering Forum and Huiqing Expressway green technology demonstration project site observation meeting. China highway society: China highway society, 2019: 201-211

11. Zy Zhang, ZhWang, L Zhang, S Wang, W Zeng. (2018) China green highway construction and evaluation technology Journal of Chang'an University (NATURAL SCIENCE EDITION), 38: 76-86 